\title{
ÍNDICE
}

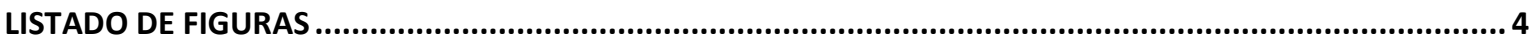

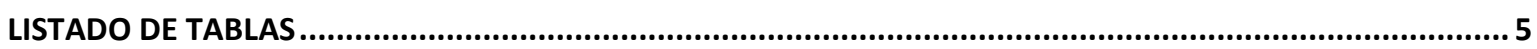

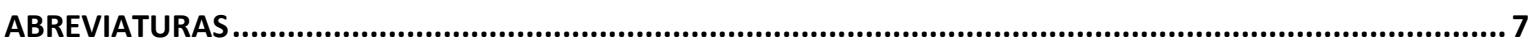

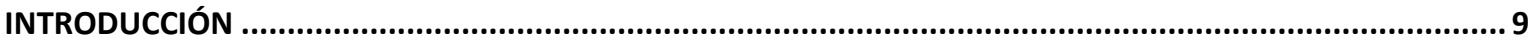

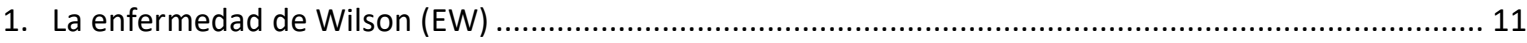

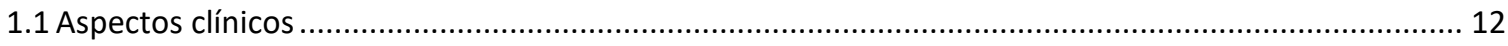

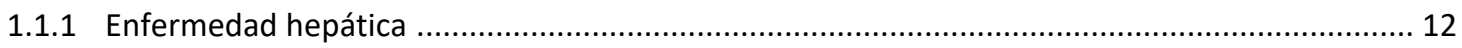

1.1.2 Enfermedad neurológica y psiquiátrica ...................................................................... 12

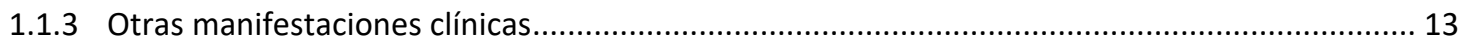

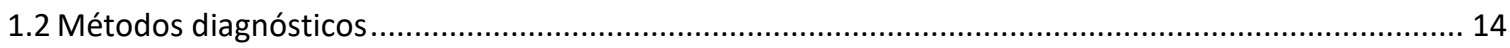

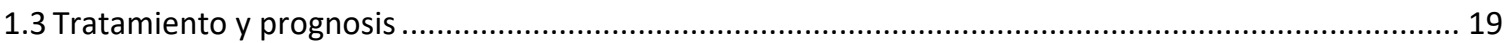

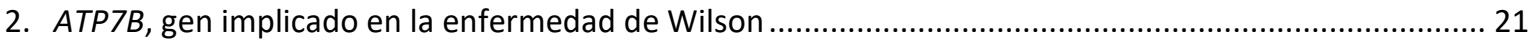

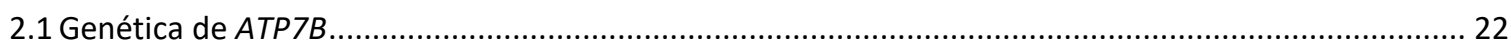

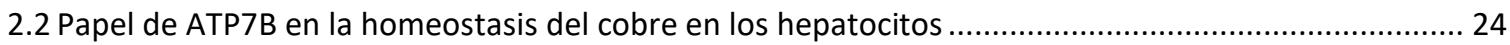

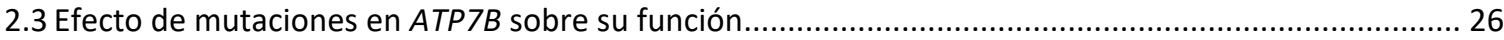

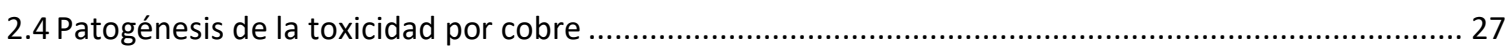

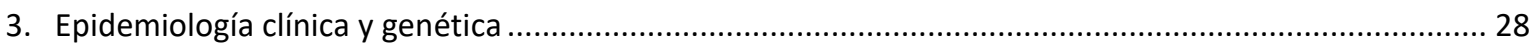

4. Factores modificadores de la enfermedad de Wilson .................................................................... 30

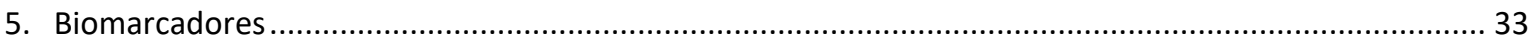

5.1 Biomarcadores en la enfermedad de Wilson y fenotipos relacionados .............................................. 33

5.2 Potencial de los miRNAs circulantes como biomarcadores .......................................................... 37

CAPÍTULO I: ESTUDIOS DE CARACTERIZACIÓN GENÉTICA EN PACIENTES CON FENOTIPO CLÍNICO DE EW. 41

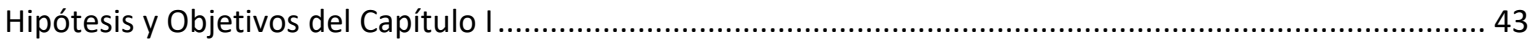

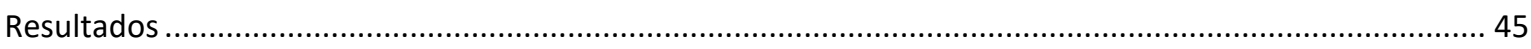

1. Cribado mutacional de $A T P 7 B$ y otros genes implicados en enfermedades hepáticas relacionadas ........ 45

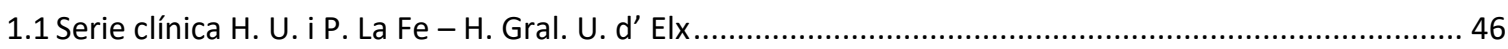

1.1.1 Variantes identificadas en ATP7B mediante secuenciación directa y MLPA ............................ 47

1.1.2 Estudio completo del gen $A T P 7 B$ mediante enriquecimiento dirigido y secuenciación masiva . 49

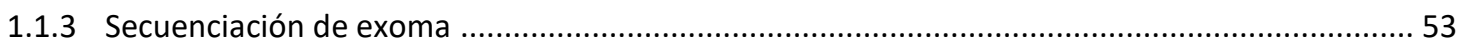

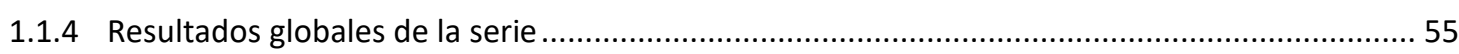

1.2 Cribado mutacional en pacientes de diferentes series.................................................................. 56

2. Estudios funcionales de expresión y regulación de variantes en $A T P 7 B$.................................................60

2.1 Caracterización de variantes de splicing en mRNA de sangre periférica y mediante ensayo de

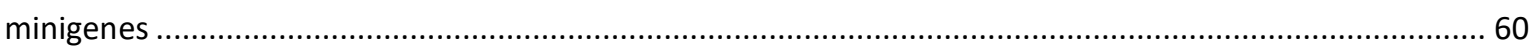

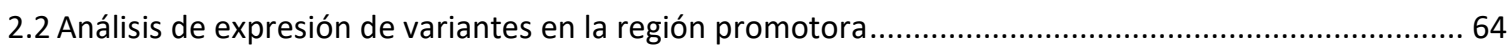

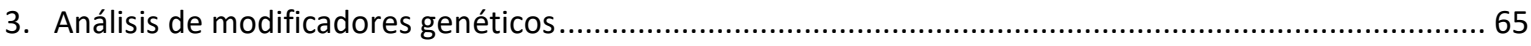

3.1 Cribado mutacional en genes implicados en el metabolismo del cobre ..........................................6 66

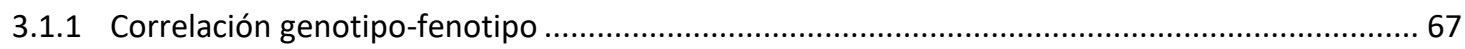

3.2 Cribado mutacional en otros genes asociados a patología .........................................................69

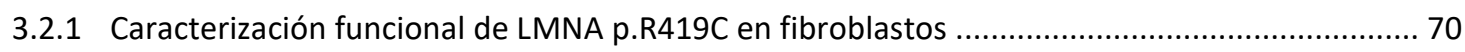

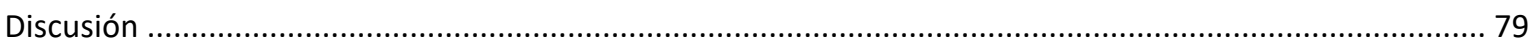

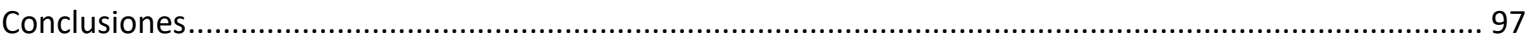




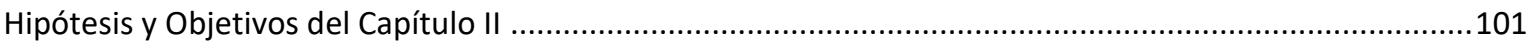

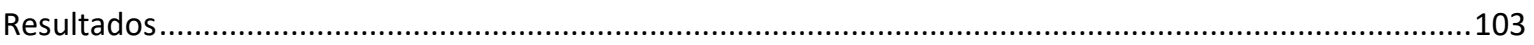

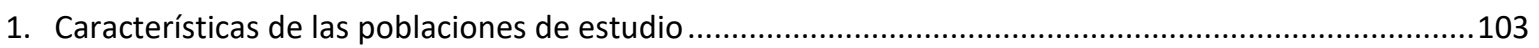

2. Determinación de miRNAs circulantes en plasma mediante miRNA-seq .............................................105

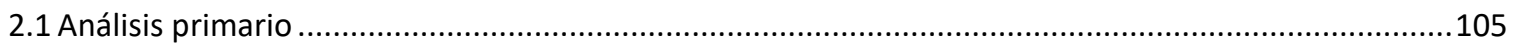

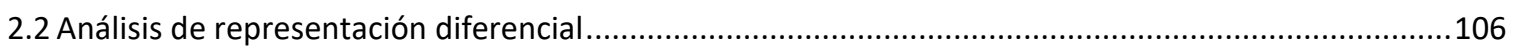

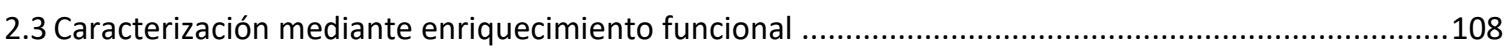

3. Perfil de miRNAs circulantes candidatos en plasma como biomarcadores .........................................109

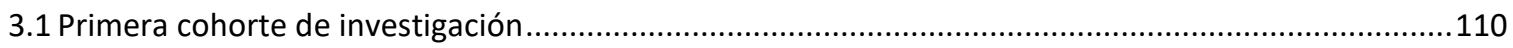

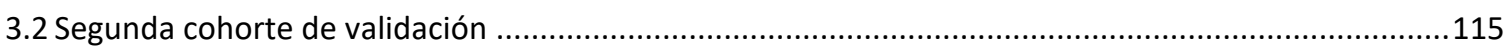

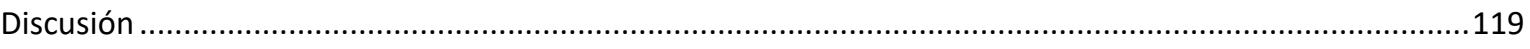

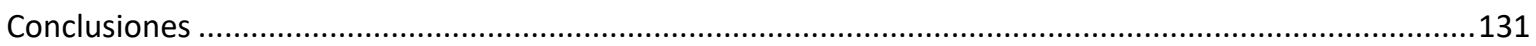

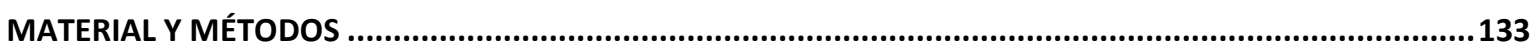

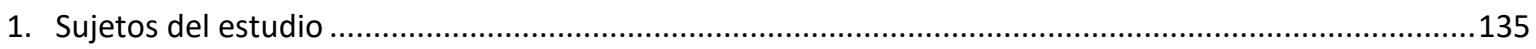

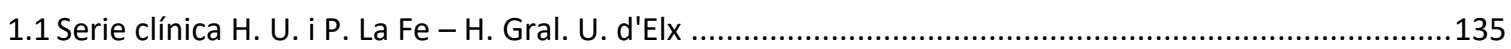

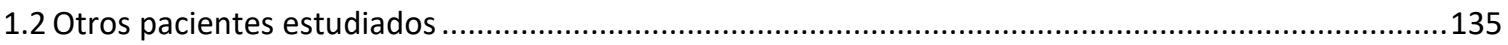

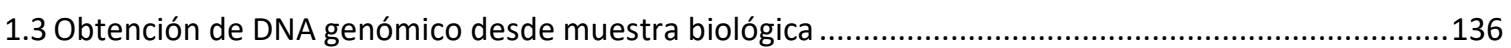

2. Análisis mutacional del gen $A T P 7 B$ y otros genes implicados en enfermedades hepáticas relacionadas 137

2.1 Estudios genéticos basados en secuenciación directa (Sanger) y MLPA ..........................................137

2.1.1 Diseño de primers para amplificación por PCR y secuenciación directa ..................................137

2.1.2 Estudio de la dosis génica mediante MLPA .......................................................................138

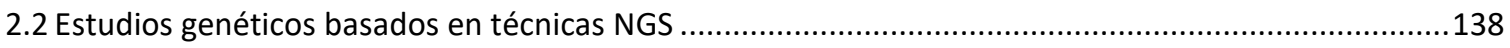

2.2.1 Análisis de $A T P 7 B$ mediante enriquecimiento dirigido y secuenciación masiva ......................138

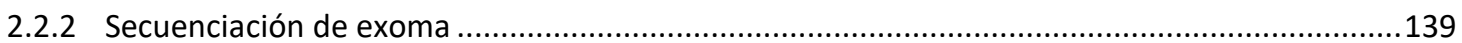

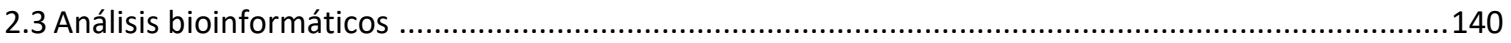

2.3.1 Análisis de las secuencias obtenidas mediante secuenciación directa (Sanger) ........................140

2.3.2 Identificación de variantes en número de copia (CNVs) mediante análisis de fragmentos .......140

2.3.3 Pipeline para análisis primario de datos de secuenciación masiva de $A T P 7 B$.........................141

2.3.4 Pipeline para anotación de variantes identificadas en secuenciación masiva ...........................142

2.3.5 Filtrado, priorización e interpretación de variantes...............................................................143

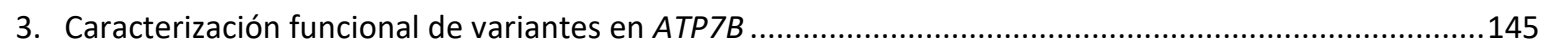

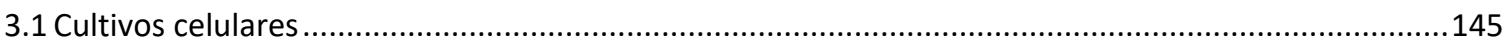

3.2 Análisis de la expresión de variantes de splicing en mRNA de pacientes ..........................................146

3.3 Análisis de la expresión de variantes de splicing mediante ensayo de minigenes .................................146

3.4 Ensayo de la actividad luciferasa de variantes en la región promotora ............................................147

4. Análisis de modificadores genéticos .........................................................................................148

4.1 Secuenciación de exoma y análisis bioinformáticos .........................................................................148

4.2 Cribado mutacional de genes y variantes candidatas mediante secuenciación directa .......................148

4.3 Estudios funcionales para la caracterización de LMNA p. R419C ........................................................149

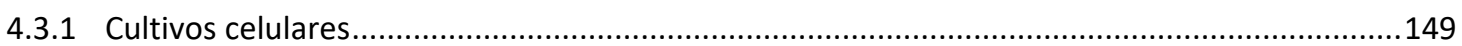

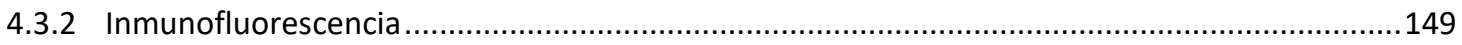

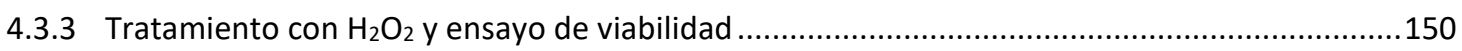

4.3.4 Estudio de la respiración y producción de $\mathrm{H}_{2} \mathrm{O}_{2}$ mitocondrial ..............................................150

4.3.5 Análisis de expresión de genes con función antioxidante mediante PCR cuantitativa (qPCR) ..152 


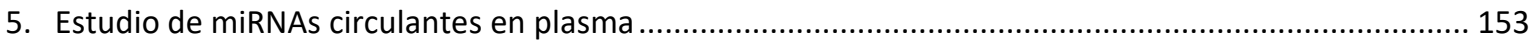

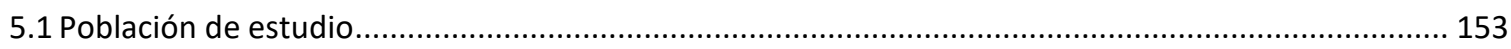

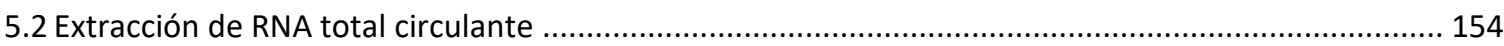

5.3 Preparación de librerías de small-RNA y secuenciación masiva .....................................................154

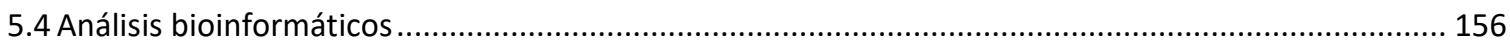

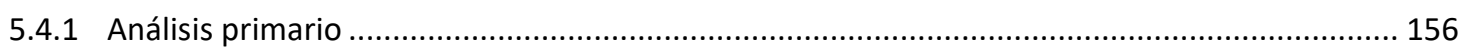

5.4.2 Análisis de representación diferencial y enriquecimiento funcional ...................................... 157

5.5 Validación de miRNAs circulantes en plasma mediante qPCR .......................................................... 157

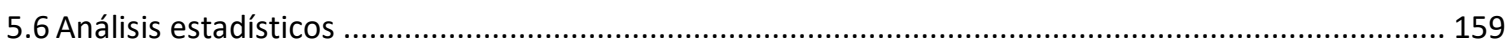

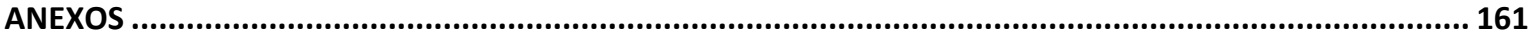

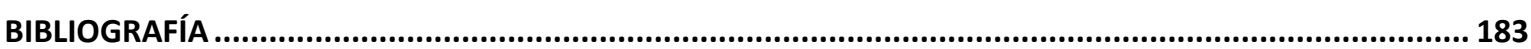




\section{LISTADO DE FIGURAS}

Figura 11: Cronología de contribuciones clave en el conocimiento de la EW ..........................................11

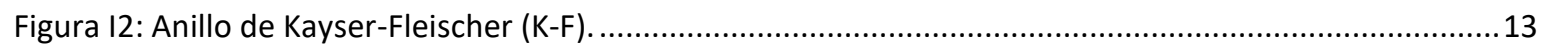

Figura I3: Histología en muestra de biopsia de hígado en pacientes con la EW..........................................17

Figura 14: Resonancia Magnética Nuclear (RMN) cerebral en pacientes con la EW..................................18

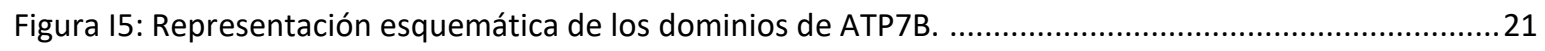

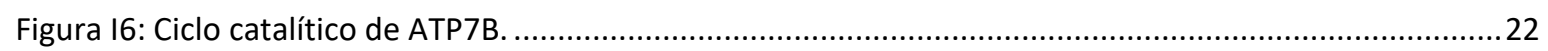

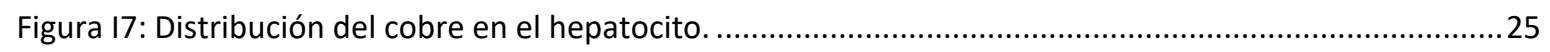

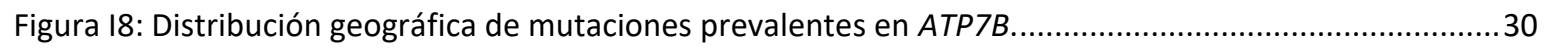

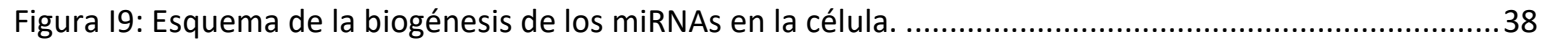

Figura R1.1: Colección de muestras para estudio genético de la EW y su distribución según el lugar de

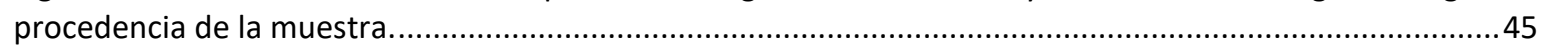

Figura R1.2: Perfil al diagnóstico de los pacientes reclutados en la serie clínica H. U. i P. La Fe - H. Gral. U. d’

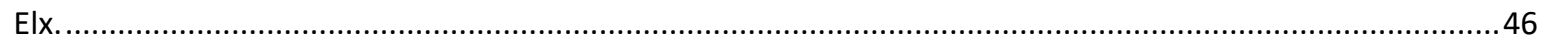

Figura R1.3: Variantes patológicas (P) y probablemente patológicas (PP) caracterizadas en ATP7B mediante secuenciación directa y MLPA en la serie clínica H. U. i P. La Fe - H. Gral. U. d' Elx.....................................48

Figura R1.4: Familias con tres variantes detectadas en ATP7B ...........................................................48

Figura R1.5: Caracterización de la deleción en el cromosoma 13 detectada en EW24 mediante secuenciación

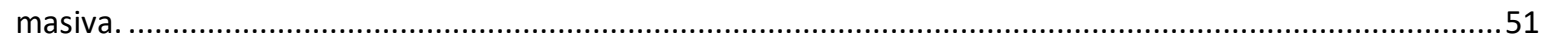

Figura R1.6: Variantes identificadas en fEW-12 mediante diferentes estrategias de análisis genético de $A T P 7 B$

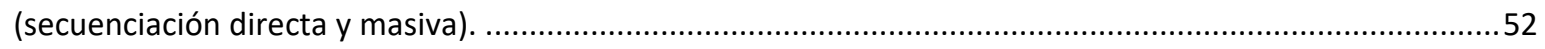

Figura R1.7: Familias investigadas mediante secuenciación de exoma. .......................................................53

Figura R1.8: Análisis de las variantes identificadas en CCDC115 ..............................................................55

Figura R1.9: Resumen del análisis genético de $A T P 7 B$ en los 25 casos índice de la serie clínica H. U. Insular Materno-Infantil - H. U. de Gran Canaria Dr. Negrín......................................................................56

Figura R1.10: Resumen del estudio genético de $A T P 7 B$ realizado en 27 casos índice procedentes de diferentes

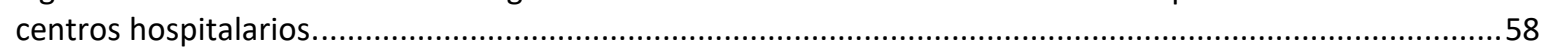

Figura R1.11: Casos singulares con diagnóstico genético de la EW. .......................................................59

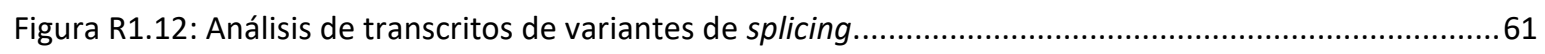

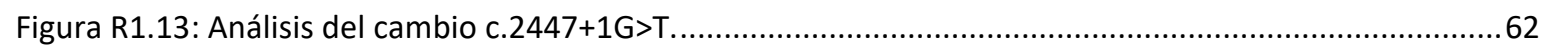

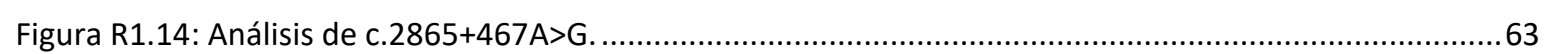

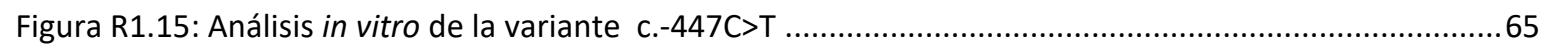

Figura R1.16: Familias con mutaciones patológicas en $A T P 7 B$ estudiadas mediante secuenciación de exoma

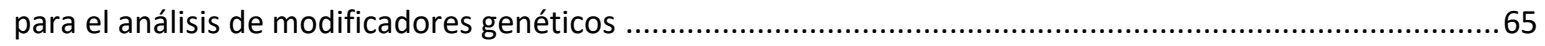

Figura R1.17: Distribución de variantes identificadas en 65 genes relacionados en el metabolismo del cobre

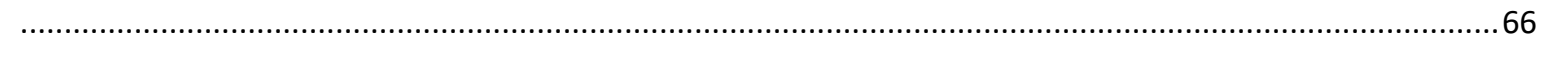

Figura R1.18: Análisis de la variante p.R419C identificada en LMNA. .......................................................70

Figura R1.19: Análisis de la morfología nuclear en fibroblastos portadores de LMNA p.R419C ...................71

Figura R1.20: Evaluación del efecto de $\mathrm{H}_{2} \mathrm{O}_{2}$ en la viabilidad celular de fibroblastos portadores de LMNA

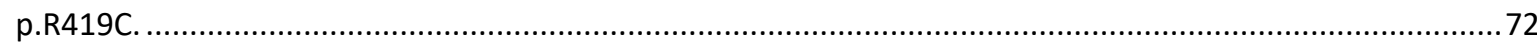

Figura R1.21: Análisis del perfil de consumo de $\mathrm{O}_{2}$ (OCR) y producción de $\mathrm{H}_{2} \mathrm{O}_{2}$ de fibroblastos LMNA p.R419C en célula intacta. 
Figura R1.22: Análisis del perfil de consumo de $\mathrm{O}_{2}(\mathrm{OCR})$ y producción de $\mathrm{H}_{2} \mathrm{O}_{2}$ de fibroblastos LMNA p.R419C en célula permeabilizada.

Figura R1.23: Análisis de los niveles de expresión de genes implicados en respuesta a estrés oxidativo en fibroblastos LMNA p.R419C mediante PCR cuantitativa (qPCR)

Figura R2.1: Control del procesamiento de lecturas obtenidas mediante miRNA-seq en las 40 muestras de la primera cohorte de investigación.

Figura R2.2: Concordancia de miRNAs maduros detectados en muestras de plasma de pacientes entre las cuatro estrategias de análisis de representación diferencial.

Figura R2.3: Validación del perfil de miRNAs circulantes en plasma mediante PCR cuantitativa (qPCR) en muestras de la primera cohorte de investigación.

Figura R2.4: Evaluación del rendimiento de los modelos de regresión logística simple para predecir el riesgo de progresión hepática. 114

Figura R2.5: Validación del perfil de miRNAs circulantes en plasma mediante PCR cuantitativa (qPCR) en muestras de la segunda cohorte de validación. .................................................................................... 117

Figura M1: Esquema del protocolo de NEBNext para preparación de librerías de small-RNA. 155

\section{LISTADO DE TABLAS}

Tabla 11: Escala diagnóstica desarrollada en la 8a Reunión Internacional sobre la EW

Tabla 12: Tipos de variantes descritas en $A T P 7 B$ y su frecuencia.

Tabla R1.1: Evaluación de la cobertura, enriquecimiento y variant calling de la herramienta NGS...

Tabla R1.2: Regiones con cobertura $<20 x$ en $A T P 7 B$.

Tabla R1.3: Haplotipo del locus $A T P 7 B$ construido con los SNPs detectados en el cribado mutacional de los pacientes de la familia fEW-60.

Tabla R1.4: Predicción in silico de $A T P 7 B$ c. $-447 C>T$.

Tabla R1.5: Variantes candidatas en genes del metabolismo del cobre relacionados con ATP7B......

Tabla R1.6: Resultado del cribado mutacional en 12 pacientes seleccionados y su descripción clínica

Tabla R1.7: Otras variantes detectadas en la ampliación del cribado mutacional en genes implicados en el metabolismo del cobre relacionados con $A T P 7 B$.

Tabla R2.1: Características clínicas y demográficas de los grupos de pacientes..................................... 103

Tabla R2.2: Características demográficas de los grupos de individuos control.

Tabla R2.3: miRNAs maduros significativamente desregulados en plasma de pacientes mediante el método QLF en los diseños 1 y 2 .

Tabla R2.4: Rutas de señalización y otros procesos biológicos de interés significativamente desregulados por los 18 miRNAs sobrerrepresentados en el grupo de pacientes de la primera cohorte de investigación...... 109

Tabla R2.5: Parámetros de los modelos de regresión logística para predecir el riesgo de progresión hepática.

Tabla M1: Filtros de calidad aplicados a variantes de tipo SNPs y a pequeñas inserciones/deleciones (indels)

Tabla M2: Parámetros utilizados para el alineamiento con Bowtie de lecturas de 16-28 pb frente a miRNAs precursores.

Tabla M3: Sondas TaqMan Advanced utilizadas para la validación de miRNAs circulantes mediante qPCR 158 